\title{
Insurability of Climate Risks
}

\author{
Arthur Charpentier \\ ENSAE and ESC Rennes Business School, Université Rennes 1, Faculté des Sciences Economiques, 7, place \\ Hoche, 35065 Rennes cedex, France. \\ E-mail: arthur.charpentier@ensae.fr
}

The IPCC 2007 report noted that both the frequency and strength of hurricanes, floods and droughts have increased during the past few years. Thus, climate risk, and more specifically natural catastrophes, are now hardly insurable: losses can be huge (and the actuarial pure premium might even be infinite), diversification through the central limit theorem is not possible because of geographical correlation (a lot of additional capital is required), there might exist no insurance market since the price asked by insurance companies can be much higher than the price householders are willing to pay (short-term horizon of policyholders), and, due to climate change, there is more uncertainty (and thus additional risk). The first idea we will discuss in this paper, about insurance markets and climate risks, is that insurance exists only if risk can be transferred, not only to reinsurance companies but also to capital markets (through securitization or catastrophes options). The second one is that climate is changing, and therefore, not only prices and capital required should be important, but also uncertainty can be very large. It is extremely difficult to insure in a changing environment.

The Geneva Papers (2008) 33, 91-109. doi:10.1057/palgrave.gpp.2510155

Keywords: cat bonds; global warming; insurability; large risks; natural catastrophes; reinsurance

\section{An introduction to climate risks}

\section{Defining climate risk}

"Climate risk" can be understood in a general setting as risks induced by climate change, for instance health issues because of new diseases (or resurgence of diseases that were supposed to have disappeared, e.g., dengue fever, malaria, cholera in North America), or the impact of climate on economics (e.g., agriculture or energy). Hence, the supply of electricity is closely related to the average temperature, with an optimum of around $20^{\circ} \mathrm{C}$. The agricultural sector is also very sensitive to climate change, such as changes around an average (sunshine, rainfall) or extreme events (frost, hail).

As mentioned by Peter Levene, chairman of Lloyd's of London, " "the real issue for insurers is natural disasters, which are a very great concern. And the impact of those disasters has been increasing because the climate has been changing, which presents some very serious challenge for insurers". Thus, what is most important for insurers, because of insolvency issues, is the impact of climate change on natural catastrophes.

\footnotetext{
${ }^{1}$ Quoted in the San Diego Union-Tribune (2004).
} 
The Geneva Papers on Risk and Insurance - Issues and Practice

92

Table 1 Impact of climate change on the insurance industry

\begin{tabular}{|c|c|c|c|c|c|c|}
\hline Examples of projected impact & Peril hazard & $\begin{array}{l}\text { Property } \\
\text { industrial }\end{array}$ & $\begin{array}{l}\text { Property } \\
\text { auto } \\
\text { marine }\end{array}$ & $\begin{array}{l}\text { Liability } \\
\text { business } \\
\text { interrupt. }\end{array}$ & Health & Life \\
\hline \multicolumn{7}{|c|}{ Higher maximum temperatures, more hot days } \\
\hline $\begin{array}{l}\text { Hospitalizations, death, serious } \\
\text { illness }\end{array}$ & Heatwave & & & & - & - \\
\hline Soil subsidence & Subsidence & - & & - & & \\
\hline Decreased ice in maritime lanes & Float ice & & + & & & \\
\hline $\begin{array}{l}\text { Increase roadway accident } \\
\text { (reaction time) }\end{array}$ & Accidents & & - & & & \\
\hline $\begin{array}{l}\text { Increased electric cooling } \\
\text { demand }\end{array}$ & Power outage & & & - & & \\
\hline \multicolumn{7}{|c|}{ Higher minimum temperatures, less cold days } \\
\hline Decrease cold related mortality & Coldwave & & & & + & + \\
\hline Extend activity of some pests & Infestation & - & & - & - & - \\
\hline Avalanche risk & Avalanche & - & & - & & \\
\hline Permafrost melt & Subsidence & - & & - & & \\
\hline \multicolumn{7}{|l|}{ Increased summer drying } \\
\hline $\begin{array}{l}\text { Damage to building } \\
\text { foundations }\end{array}$ & Subsidence & - & & & & \\
\hline $\begin{array}{l}\text { Decrease water resource } \\
\text { quantity }\end{array}$ & Drought & & & - & - & \\
\hline Increase risk of wildfire & Wildfire & - & - & - & - & - \\
\hline
\end{tabular}

Source: Mills et al. (2005).

Climate change and global warming from an insurance perspective

We will define "global warming" as the long-term (from an economic perspective, not a geophysical one) climate change. But one should also note that climate change does not only have a negative impact (for insurers). Table 1 shows the impact of climate change on some risks, inspired by Mills et al., " where "+" stands for "positive" financial impact (a gain). Figure 1 also helps to understand and quantify climate change in major cities: it represents the evolution of the temperature in Paris over one century ( +3 degrees), with the distribution of winter and summer temperature over a 20 -year period, at the beginning of the 20th century (1900-1920) and at the end (19802000).

\section{From global warming to catastrophes}

As mentioned already in the previous section, the most important aspect is that climate changes will increase the intensity and the frequency of climate hazards ${ }^{3}$ even if it is

\footnotetext{
${ }^{2}$ Mills et al. (2005).

${ }^{3}$ See, for example, McGuire et al. (2002).
} 

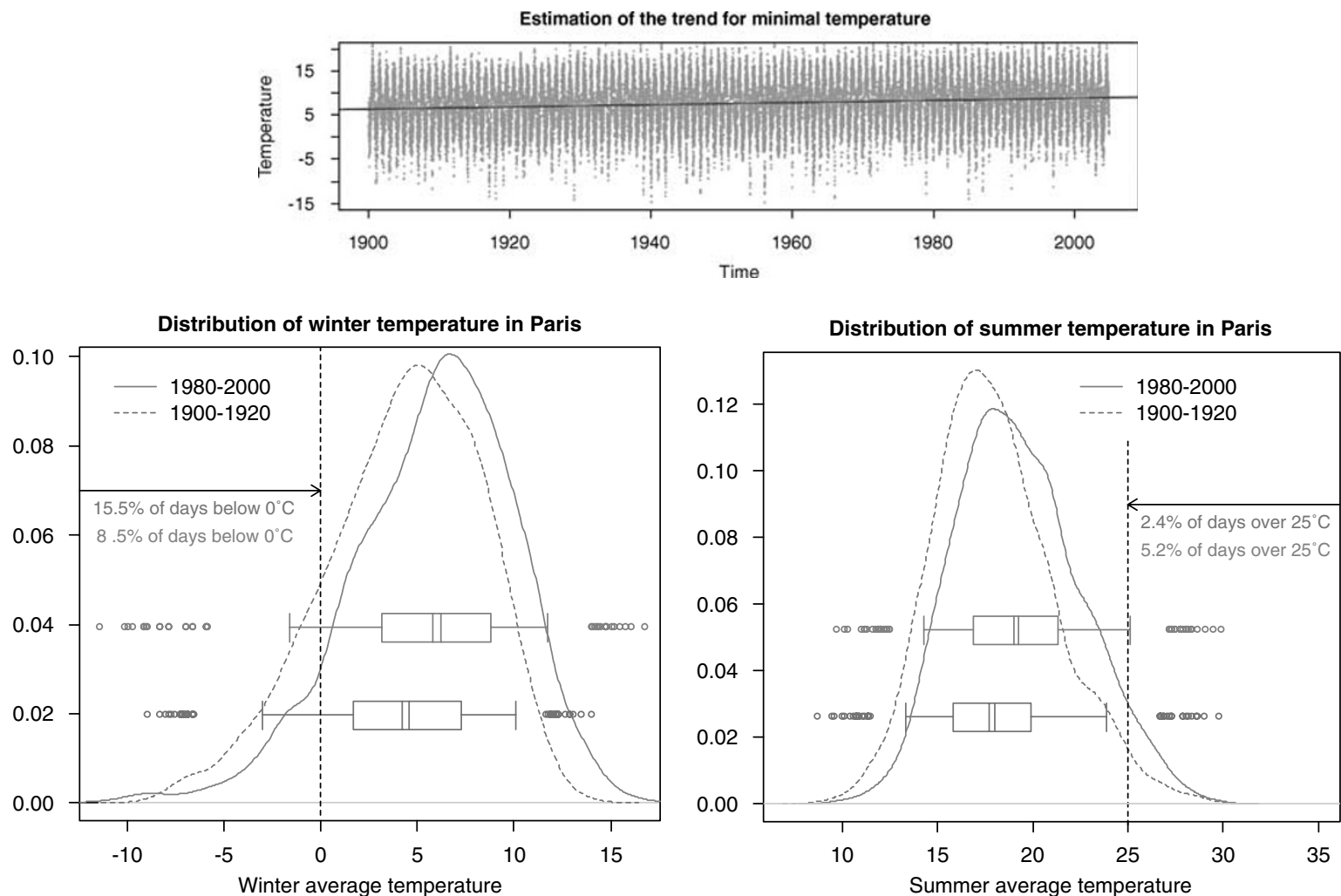

Figure 1. Temperature in Paris, over one century, and distribution of winter and summer temperature for periods 1900-1920 and $1980-2000$ (including boxplot with $95,75,50,25$, and 5 per cent quantiles). 
The Geneva Papers on Risk and Insurance - Issues and Practice

94

Table 2 The 10 most expensive catastrophes, 1950-2005

\begin{tabular}{|c|c|c|c|c|c|}
\hline Date & Loss event & Region & Overall loss & Insured loss & Fatalities \\
\hline 25.8 .2005 & Hurricane Katrina & U.S.A. & $1,25,000$ & 61,000 & 1,322 \\
\hline 23.8.1992 & Hurricane Andrew & U.S.A. & 26,500 & 17,000 & 62 \\
\hline 17.1.1994 & Earthquake Northridge & U.S.A. & 44,000 & 15,300 & 61 \\
\hline 21.9.2004 & Hurricane Ivan & U.S.A., Caribbean & 23,000 & 13,000 & 125 \\
\hline 19.10.2005 & Hurricane Wilma & Mexico, U.S.A. & 20,000 & 12,400 & 42 \\
\hline 20.9.2005 & Hurricane Rita & U.S.A. & 16,000 & 12,000 & 10 \\
\hline 11.8 .2004 & Hurricane Charley & U.S.A., Caribbean & 18,000 & 8,000 & 36 \\
\hline 26.9.1991 & Typhoon Mireille & Japan & 10,000 & 7,000 & 62 \\
\hline 9.9.2004 & Hurricane Frances & U.S.A., Caribbean & 12,000 & 6,000 & 39 \\
\hline 26.12.1999 & Winter storm Lothar & Europe & 11,500 & 5,900 & 110 \\
\hline
\end{tabular}

Source: Munich Re (2006).

scientifically impossible to blame the greenhouse effect for powerful hurricanes or major storms or floods in Europe. As quoted in Leggett, "the increased intensity of all convective processes in the atmosphere will force up the frequency and severity of tropical cyclones, tornados, hailstorms, floods and storm surges in many parts of the world, with serious consequences for all types of property insurance". 4 This was confirmed recently by Emanuel, for hurricanes and cyclones at least: "future warming may lead to an upward trend in a tropical cyclone's destructive potential, and a substantial increase in hurricane-related losses in the 21 st century". 5

Of the 10 most expensive natural catastrophes over the past 56 years, six occurred in 2004 and 2005 (see Table 2).

However, one should note that not only is climate change to blame, but that human actions also are partially responsible for these major natural catastrophes (e.g., flood events are not only due to rainfall but also linked to the stability of soil structures or natural slopes which can be influenced by human constructions). These two factors increase the risk simultaneously, both affecting frequency as well as loss amounts.

The following section of this paper will come back to the conditions necessary for insurability, focusing on actuarial conditions (finite premium, diversification, quantifiable risks, etc.) and economic ones (no adverse selection, insurers' willingness to pay the premium proposed by insurance companies, etc.). And, as we will see, climate risks are hardly insurable. The only possibility is to be able to transfer these risks, either to (classical) reinsurance markets, or also, due to the lack of capacities, to capital markets. The next section will present all the possible techniques for transferring large risks. Finally, the last section will highlight one of the most challenging parts of climate risk: climate change. Is it simple to insure in a changing environment? How do insurance companies manage to forecast future losses? This additional uncertainty is, without a doubt, the most challenging aspect for the insurance industry, and the most risky one too, from a solvency perspective.

\footnotetext{
${ }^{4}$ Leggett (1993).

${ }^{5}$ Emanuel (2005).
} 


\section{Insurability: when can we sell/buy insurance?}

Insurance is usually defined as "the contribution of the many to the misfortune of the few". Some risk adverse agents (called the insured) are willing to pay even more than the actual value of predictable risk to transfer its consequences to another agent (called the insurer). Hence, the fundamental concept is the mutualization of risks by the insurer. Following the ideas of Berliner, ${ }^{6}$ it is possible to define criteria so that a risk can be insured.

1. Judicially, an insurance contract can be valid only if the claim occurrence satisfies some randomness property. This is the concept of legal insurability.

2. The possible maximum loss should not be huge with respect to insurer's solvency.

3. The average cost should be identifiable and quantifiable.

4. Risks should be pooled so that the law of large numbers can be used (independent and identically distributed claims).

Points 2-4 yield the concept of actuarial insurability.

5. There should be no moral hazard, and no adverse selection,

6. There must exist an insurance market, that is, the supply and the offer should meet, and an equilibrium price should arise.

These two points are sometimes related to market imperfections and can be related to some general concept of economic insurability.

\section{Legal insurability: randomness properties}

The first point is rather important. As mentioned in the first article of French Law 82-600 of 13, July, 1982 (since natural catastrophes are covered by a public mechanism, natural catastrophes are defined by the law), "are considered as consequences of natural catastrophes all direct damages caused by abnormal intensity of natural hazard, when standard measures usually taken to prevent those events did not prevent its occurrence". But what does "abnormal intensity of natural hazard" mean? Is it "abnormal" to have recurrent floods in some areas easily flooded (in a former river channel)? This notion can be related to the notion of "known risks" and will be discussed later.

\section{Actuarial insurability: the problem of large risks non-diversifiable}

The second and third points describe the ability to identify and quantify the chances of an event to occur, as well as the extent of losses. And, as observed already in Zajdenweber, ${ }^{7}$ it might not be satisfied in the case of natural catastrophes. A natural idea can be to fit a Pareto distribution to the distribution of the losses, for the largest claims. Recall that for the Pareto distribution,

$$
F(x)=P(X \leqslant x)=1-\left(x / x_{0}\right)^{b} \text { or } \log [1-F(x)]=a+b \log x
$$

where $x_{0}=\exp (-a / b)$.

\footnotetext{
${ }^{6}$ Berliner (1982).

${ }^{7}$ Zajdenweber (1996, 2001).
} 


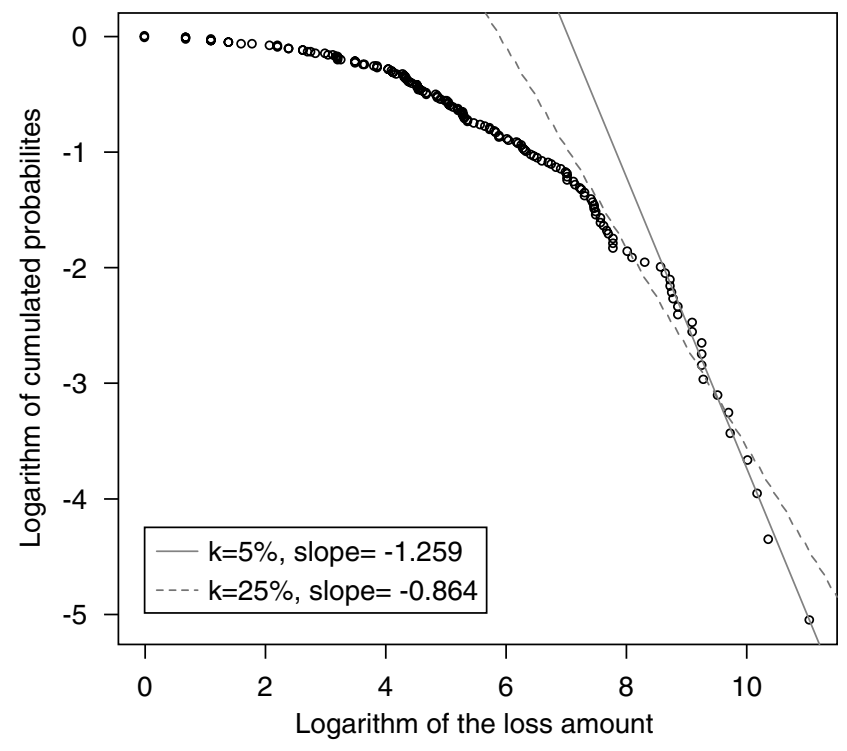

Figure 2. Adjusting a Pareto distribution to hurricane losses, the log-log Pareto plot.

Hence, in the case of the scatterplot of $\log X_{i}$ versus $\log \left[1-\hat{F}\left(X_{i}\right)\right]$ being on a straight line, the claims are Pareto distributed, and the slope is $b$. Note that if $-b \geqslant 1$, then $E(X)$ is infinite.

Example: Based on the dataset studied in Pielke and Landsea ${ }^{8}$ on hurricane losses, Figure 1 presents a scatterplot of $\log X_{i}$ versus $\log \left[1-\hat{F}\left(X_{i}\right)\right]$, including the adjustment of a straight line, based on the 25 per cent largest losses (dotted line) and the 5 per cent largest losses (plain line). In the first case, the slope is -0.86 , that is, even if the variance is infinite, the expected value is finite, but in the second case, the slope is -1.26 , and therefore, the expected value is infinite. As in Charpentier, ${ }^{9}$ a more detailed analysis should be performed to assess more precisely whether the pure premium is finite or not, but at first sight we can say that - at least - losses can be extremely large (Figure 2).

Those two points are also related to the concept of risk (with known probabilities) and uncertainty or ambiguity: ${ }^{10}$ risk should be based on probabilistic uncertainty.

The fourth point is also an important issue since the central limit theorem (based on independence of claims) helps to derive confidence intervals, and thus, to assess additional capital required for solvency purposes or safety margins in premium calculation. In case of positive dependence (e.g., geographical dependence, where thousands of claimed policies are from a common event), capital should increase (see Figure 3) since quantiles will increase, while the pure premium will remain unchanged.

\footnotetext{
${ }^{8}$ Pielke and Landsea (1998).

${ }^{9}$ Charpentier (2007).

${ }^{10}$ See, for example, Knight (1921).
} 


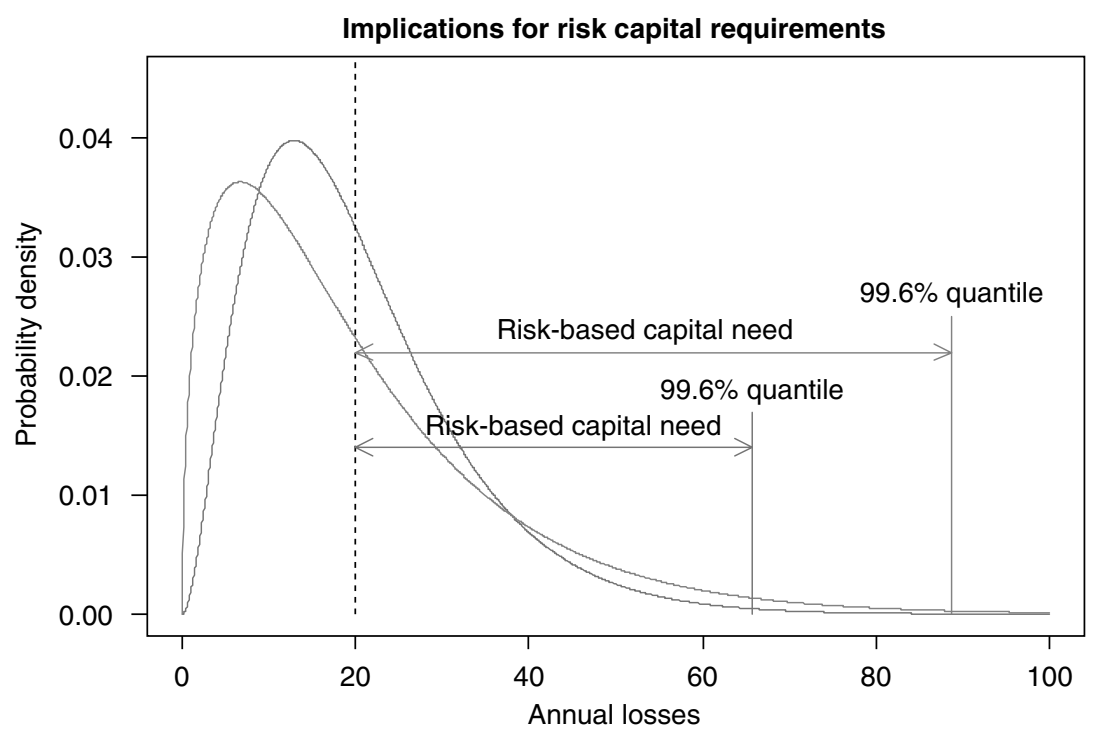

Figure 3. Impact of dependence on capital requirements.

One of the challenges of natural catastrophes is that they can jeopardize the solvency of insurance and reinsurance markets. Defining a catastrophe is quite difficult, but as mentioned, for example, in Kunreuther, ${ }^{11}$ a key concept is the geographic area, and an induced strong correlation among the losses in their portfolio (thousands of policies hit, for several lines of business - property, car insurance, life insurance for casualties, business interruption, etc.). Hence, diversification is no longer possible. Note that Mayers and $\mathrm{Smith}^{12}$ already pointed out that catastrophe risks were hardly diversifiable.

Economic insurability: the problem of finding a fair price

With regard to economic insurability, adverse selection is a difficult issue, since major natural events can be covered only when pooling a large number of insured. In that case, risks are hardly homogeneous (non-coastal regions being usually less risky for instance). Further, moral hazard is also hard to deal with, especially in the case of natural catastrophes. Recall that in some countries, the premium to insure against floods is related to prevention measures (and is controlled by the NFIP in the United States).

And, finally, the last point is perhaps the most difficult one to satisfy, as shown in the following example.

\footnotetext{
${ }^{11}$ Kunreuther (2001, 2006).

12 Mayers and Smith (1982).
} 
98

Example: Kunreuther and Pauly ${ }^{13}$ mention a comment from Business Insurance in 2001: "my dwelling is insured for $\$ 2,50,000$. My additional premium for earthquake insurance is $\$ 768$ (per year). My earthquake deductible is $\$ 43,750$ [...] The more I look to this, the more it seems that my chances of having a covered loss are about zero. I'm paying $\$ 768$ for this?' Since the annual probability of an earthquake in Seattle is around $1 / 250=0.4$ per cent and the actuarial implied probability is $768 /(2,50,000-43,750)=0.37$ per cent it appears that the premium asked is fair from an actuarial point of view, and that the insurance company cannot ask less than the pure premium. Thus, in this case, it is hard to find an equilibrium price that both the insured and the insurer accept. Many individuals perceive the probability of a disaster as a very low-probability event, and therefore find it unnecessary to invest in protective measures: "we live from payday to payday", as mentioned in Kunreuther et al. ${ }^{14}$ It was also noticed that the householder's decision either to mitigate or not is based on a time horizon of 30 years. More precisely when facing ambiguity, insurance companies can also use cautious and safe premiums, with an additional loading.

\section{Transferring large risks: reinsurance and ART}

Based on these remarks, it appears that natural catastrophes are hardly insurable. Kleindorfer and Kunreuther" ${ }^{15}$ already observed that "the private insurance industry feels that it cannot continue to provide coverage against hurricanes and earthquakes as it has done in the past without opening itself up to the possibility of insolvency or a significant loss of surplus". The only possibility is to transfer very large risks, exceeding a predefined limit (e.g., when the pure premium is infinite).

Development of the capital markets followed the shortage of reinsurance following Hurricane Andrew (1992) and the Northridge earthquake (1994). Alternative Risk Techniques can be used to solve the following three challenges:

- Finding additional capacities for insurance and reinsurance markets, especially in the case of a hard market, where traditional capacities of a reinsurance market are constrained. This was the goal of Zenkyoren (the National Mutual Insurance Federation of Agricultural Cooperatives) in Japan in 2003, which was looking for capacities to provide insurance cover for a second event.

- Avoiding the credit risk of reinsurers, since liabilities are collateralized in bonds.

- Getting an actuarial price for these products, with consistency over time: reinsurance markets are very sensitive to catastrophes (until 2001 Chicago Airport paid a premium of $\$ 0.125$ million for a $\$ 750$ million cover, and following $9 / 11$ the premium was $\$ 6.9$ million for a $\$ 125$ million cover), while financial markets react more softly: When typhoon Charley was destroying the Caribbean and Cuba in

\footnotetext{
${ }^{13}$ Kunreuther and Pauly (2004).

${ }^{14}$ Kunreuther et al. (1978).

${ }^{15}$ Kleindorfer and Kunreuther (1999).
} 
2004, secondary markets became more active, with $\$ 15$ million bonds traded while the hurricane was approaching the U.S., with higher volatility but prices remaining in a thin range.

\section{(Traditional) reinsurance: excess of loss and "cat" excess of loss treaties}

In reinsurance excess of loss (stop loss) treaties, the reinsurer undertakes the upper layer of the risk, after a certain attachment point. In classical reinsurance treaties, the trigger is indemnity based (the reinsurance company pays some indemnity when actual losses exceed a given threshold called priority). From an economic perspective, there is moral hazard in these contracts since the trigger is related only to actual losses of the insurance company (claims being settled by the insurance company). Furthermore, there is also a credit default issue: if the reinsurance company defaults, the insurance company still has to pay back losses to the insured, but will not be reimbursed by the reinsurance company. The first drawback can explain the interest for alternative triggers (based on industry or environmental indices); the second one can explain the interest for securitization and capital market-based solutions.

In classical excess of loss treaties, the reinsurer pays when a single policy claims a loss. For "cat" excess of loss treaties the reinsurer pays an indemnity based on the total loss due to a single natural event (a flood, a hurricane, etc.). The main difficulty is to define precisely the event or a single natural event. This point will be developed afterwards when defining a catastrophe event.

\section{(Traditional) reinsurance: limited capacities}

Given the limitation of the reinsurance capacities, that is, the amount of reinsurance that insurance companies can afford to purchase, insurance companies have been concerned with probable maximum loss that can be experienced. One should note that this concern is not only theoretical: as mentioned in Conning et al., ${ }^{16}$ nine insurance companies in Florida were insolvent following hurricane Andrew.

As the size of catastrophes increases, the limitation of reinsurance markets emerges: if the risk is too large to aggregate and diversify, the reinsurance industry (as a whole) might not be able to provide sufficient capital to cover a loss. For the top ten reinsurance companies, total net written premium represents $\$ 72$ billion in 2005 and for the top 20, $\$ 90$ billion. ${ }^{17}$ This capital can be compared to the $\$ 49$ billion paid for catastrophes in 2004, and \$86 billion in 2005 .

For more details on the pricing of reinsurance treaties against catastrophic losses, see Cummins et al. ${ }^{18}$

Alternative reinsurance: captives, industry loss warranties, sidecars

Additional capacities can be brought into the market through captives, sidecars and industry loss warranties (ILW). On the one hand, captives and side cars are simply

\footnotetext{
${ }^{16}$ Conning et al. (1994).

${ }^{17}$ Swiss Re (2006).

${ }^{18}$ Cummins et al. (1999).
} 
dedicated reinsurance vehicles, with quota share covers (it is simply a hedge fund that wishes to get into the reinsurance business and will start a special purpose vehicle with a reinsurer). On the other hand, ILW pay a fixed amount based on the amount of industry loss (e.g., Property Claim Services (PCS) or SIGMA).

\section{Financial reinsurance: cat options and cat bonds}

In the case of catastrophe bonds, the issuing company enters into a reinsurance treaty with a special purpose vehicle (SPV), which converts insurance risk into financial or investment risk. The cedent pays a premium to the SPV in exchange for loss payments in case an event occurs. The SPV issues securities to finance this coverage. Investors purchase securities by paying the principal, and they receive interest payments equal to a risk-free rate (e.g., LIBOR) plus a risk premium, less loss payments that may be made.

Financial options can also be used to hedge against large losses. Options are securities that give the purchaser the right to buy something (usually the underlying security, i.e., an asset, a basket of assets, an index, or even another derivative) to the seller at a predetermined price and for a specified period of time. Similarly, exchangetraded catastrophe options are standardized contracts bought and sold through an organized market (e.g., CBOT, the Chicago Board of Trade). Catastrophe options give the purchaser the right to a cash payment if a specified index of catastrophe losses reaches a specified level - the strike price. Hence, these options work much like excess reinsurance.

Example: CBOT's PCS Catastrophe Insurance Options began trading in September 1995. They are European cash options (they are settled in cash, only at the expiration of the contract - either 6 or 12 months after the end of the loss period). Loss periods are generally calendar quarters, and estimates of aggregate industry catastrophic losses are made daily by PCS. They provide an index, where each index point is equivalent to $\$ 100$ million of aggregate industry catastrophe losses. ${ }^{19}$

\section{"The government as the ultimate risk manager"}

In several countries (France, Spain, Norway, Switzerland) there is an "unlimited government guarantee" for catastrophes. In case of such a public mechanism, riskfinancing instruments can also be considered (catastrophe tax, government debt instruments, international loans), but it is not (ex ante) insurance anymore. Therefore, we will not expand further on this point. ${ }^{20}$

\section{Defining a natural catastrophe}

In single-event reinsurance, the main difficulty is to define clearly - and without ambiguity - the event.

Example: In December 1999, two major winterstorms crossed Europe within 48 hours, Lothar and Martin. There were intense discussions between cedents and

\footnotetext{
${ }^{19}$ See Gorvett (1999) for a detailed description of these products.

${ }^{20}$ See, for example, Moss (2004) for a detailed study.
} 
reinsurers to decide if there were one or two storms. In this particular case of two large storms, reinsurers were arguing that this was a single event (and they therefore should pay for a single layer, not two). For smaller events, they would have argued that there were several events, so that none of them may reach priority.

Four techniques can be considered to define the trigger (and so the event):

- indemnity trigger: directly connected to the experienced damage (for classical reinsurance),

- industry-based index trigger: connected to the accumulated loss of the industry (e.g., PCS for ILW),

- environmental-based index trigger: connected to some climate index (rainfall, windspeed, Richter scale, etc.) measured by national authorities and meteorological offices (e.g., EuroNextWeather andd Metnext indices, produced by Meteo France, Powernext and Euronext),

- parametric trigger: a loss event is given by a cat-software, using climate inputs and exposure data.

\section{Insuring in a changing environment}

Insurance policies are usually renewed annually and, therefore, insurers have to set an appropriate premium level (with a given cover for the coming year) with a lot of uncertainty about systematic change or short-term trend. Warren Buffet already pointed out in 1992 that "catastrophe insurers can't simply extrapolate past experience. If there is truly global warming, for example, the odds would shift, since tiny changes in atmospheric conditions can produce momentous changes in weather patterns". Many other authors mentioned this point. For instance, as quoted in Banham, "insurers are making huge assumptions that the past will be the key to the future. We have at hand about 110 years of recorded observations of global climate activity. I can tell you with certainty that we have not seen the range of climate variation in that time". ${ }^{21}$ This was also mentioned by $\mathrm{Nott}^{22}$ who observed that some extremely large events were not necessarily unusual, based on a very long time horizon.

Note that two factors increase risks:

- the increase of frequency that can be related to global warming (for atmosphericrelated claims);

- the increase of value-at-risk, due to the increase of concentration of wealth in risky areas (Florida, California, Japan).

\section{Increasing frequency}

The Intergovernmental Panel on Climate Change (IPCC) stated in its 2001 Third Assessment report that: "peak wind intensity and mean and peak precipitation

\footnotetext{
${ }^{21}$ Banham (1995).

22 Nott (2003)
} 


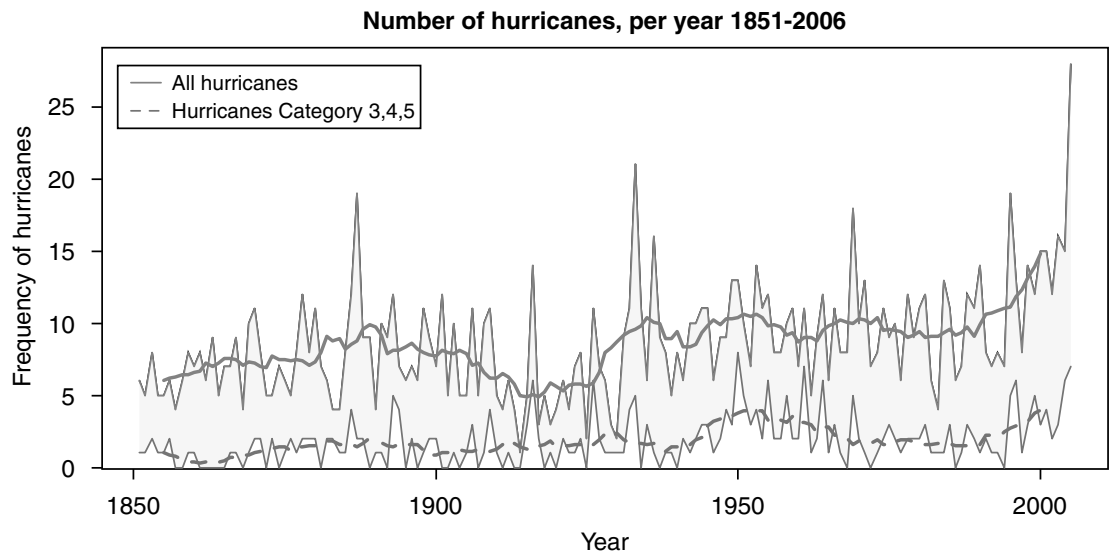

Figure 4. The increasing trend of hurricane frequency, from 1851 to 2006, with yearly number of hurricanes (thin lines), and 10-year moving average.

intensities of tropical cyclones are likely to increase". ${ }^{23}$ As shown in Webster et al. ${ }^{24}$ the number of category four and five hurricanes has doubled over the past 35 years (see also Figure 4 for a longer trend graph). As they highlight, "this trend is not inconsistent with recent climate model simulations that a doubling of $\mathrm{CO}_{2}$ may increase the frequency of the most intense cyclones although attribution of the 30 -year trend to global warming would require a longer global data record and, especially, a deeper understanding of the role of hurricanes in the general circulation of the atmosphere and ocean, even in the present climate state". ${ }^{25}$ A heuristic explanation is that hurricanes get their energy from warm water and, as global warming progresses, the world's oceans warm. As the oceans warm there is more energy available to feed hurricanes. Note that meteorologists are still arguing whether the change is due only to climate change or if it is a long-term cycle. But even if there is no strict consensus on the link between global warming and increasing trends in extreme hurricane events ${ }^{26}$ for a short-term perspective (as in insurance pricing), policyholders in Florida are very likely to face a large hurricane in a close future.

This increase of frequency can be observed for hurricanes (see Figure 4) in the United States, as well as coastal floods, and also in Europe for major winter storms.

\section{Increasing value-at-risk}

To illustrate this second point recall that in 1950 only New York could be considered a mega city with more than 10 million inhabitants, while 26 of such cities are expected to

\footnotetext{
${ }^{23}$ IPCC (2001, p. 11).

${ }^{24}$ Webster et al. (2005).

${ }^{25}$ See also Knutson and Tuleya (2004).

${ }^{26}$ See, for example, Landsea et al. (2006).
} 
exist by 2015 (most in high natural risk prone area, such as Tokyo, Shanghai, New York or Los Angeles). Moreover, the value-at-risk of costal areas in the United States increased by 69 per cent from 1993 to 1998, to reach $\$ 3,150$ billion in 1998. In Florida, 80 per cent of the insured assets are located near the coasts (with a total exposure around $\$ 2$ trillion, similar to the exposure in New York).

In Europe, London is a well-known example of major city that can be devastated by a flood if everything remains unchanged. As a warning, during the 2007 summer the worst floods in 60 years hit England.

\section{From intuitive perception to risk models and actuarial prices}

The architecture of catastrophe models are based on three main components:

- the hazard module, which generates stochastic climate scenarios and assesses perils;

- the engineering model (based on the exposure, the values, the building) which calculates damage;

- the insurance module, which quantifies financial losses based on deductibles and reinsurance (or retrocession) treaties.

Using simulations to generate scenarios started in the $1970 \mathrm{~s} .{ }^{27}$ But cat-softwares were developed only at the end of the 1980s (AIR in 1987, RMS in 1988). The interest for those models came in the 1990s, following the two large-scale events of 1989 (hurricane Hugo in September in South Carolina, \$4 billion; and the Loma Prieta earthquake in October 1989 in the San Francisco peninsula, \$6 billion ${ }^{28}$ ). Those two events were a warning, and the main signal was hurricane Andrew, in August 1992, where AIR estimated the loss at the unbelievable level of $\$ 13$ billion, within hours of landfall.

The model characterizes the risk of natural phenomena, such as projected path and wind speed for hurricanes, including the frequency of certain magnitudes or frequencies. Hence, since a tropical cyclone requires a large expanse of warm ocean water, those cyclones are most likely to form between $5^{\circ}$ and $20^{\circ}$ latitude. The determination of the annual probability of occurrence of natural events is the most uncertain module of the model's hazard. For one scenario, the model generates the storm's source parameters and simulates the storm's movement along a track. Local windfields are generated by calculation of maximum over-water wind speed. Wind duration is also a key element to get damage estimation. The model characterizes the inventory, or portfolio of properties, such as location (geocoding, based on latitude and longitude, or ZIP codes). Those factors enable the calculation of vulnerability (or susceptibility to damage). Not only surveying the inventory of building is necessary, but also building performance (or fragility).

A major challenge for cat-softwares (RMS, EQECat) is the first module: how to generate consistent future scenarios based on past experience? Even if those models learn by experience each time, estimations of insured losses are far from estimated values. Consider the example of Kyrill, a European windstorm, forming an

\footnotetext{
${ }^{27}$ See Inman and Conover (1980).

${ }^{28}$ See Stover and Coffman (1993).
} 
The Geneva Papers on Risk and Insurance - Issues and Practice

104

Table 3 Kyrill best estimate losses from a European insurance group

\begin{tabular}{|c|c|c|c|c|c|}
\hline & \multirow{2}{*}{$\begin{array}{l}\text { Local entities } \\
\text { best estimate }\end{array}$} & \multirow{2}{*}{$\begin{array}{c}+ \text { a safety } \\
\text { margin }\end{array}$} & \multirow{2}{*}{$\begin{array}{c}\text { Market share } \\
\text { assessment }\end{array}$} & \multicolumn{2}{|c|}{ Catastrophe models } \\
\hline & & & & Minimum & Maximum \\
\hline France & 10 & 15 & 45 & 8 & 67 \\
\hline Belgium & 30 & 35 & 30 & 8 & 34 \\
\hline United Kingdom & 31 & 36 & 35 & 68 & 164 \\
\hline Ireland & 1 & 1 & 0 & 1 & 35 \\
\hline Netherlands & 9 & 10 & 8 & 5 & 22 \\
\hline Germany & 120 & 140 & 140 & 99 & 114 \\
\hline Switzerland & 1 & 3 & 3 & 1 & 9 \\
\hline Total & 202 & 240 & 261 & 190 & 445 \\
\hline
\end{tabular}

extra-tropical cyclone with hurricane-strength winds, which crossed Europe in January 2007. Table 3 presents estimated losses with market-based estimated losses versus estimations provided by several cat-softwares. Note that the range of estimated losses per country is rather large (e.g., from 8 million to 67 million for France), but also that all the models either underestimate (e.g., Germany) or overestimate (e.g., United Kingdom).

Recall $^{29}$ that scenarios are already quite pessimistic: a hurricane of level four hitting Miami will cost more than $\$ 100$ billion; the centennial Mississippi flood will cost more than $\$ 34$ billion (only a short proportion paid by the insurer because of the National Flood Insurance Program); a winter storm in the North East (as in 1998 in Canada) will cost more than $\$ 20$ billion; a major forest fire in California or in France, more than $\$ 9$ billion.

\section{The challenge of updating probabilities}

One challenging problem with natural catastrophes is that, on the one hand, once society is alerted to the risk, it may take preventive actions (e.g., reinforcing buildings) that will make the risk less likely to occur, or less expensive in the future, and therefore the premium should decrease. On the other hand, by updating the event probabilities, or the distribution of the losses, the premium should therefore increase. ${ }^{30}$ Recall that before 1989 no natural disaster in the United States ever caused more than a \$1 billion in insured losses, until hurricane Hugo shattered this record. The worst case scenario was then $\$ 8$ billion, until hurricane Andrew in 1992, which caused more than $\$ 15$ billion insured losses. And finally Katrina in 2005 reached the unforeseen level of $\$ 40$ billion. One can hardly say what might be the next one. Those doubts about the ability

\footnotetext{
${ }^{29}$ See www.rms.com

${ }^{30}$ See Cutler (1996).
} 
of meteorologists, engineers or actuaries to predict future catastrophic losses, based on past experience, have frightened several insurers.

\section{The puzzle of assessing estimations in a changing environment}

Uncertainty was rather large for hurricanes, but it becomes impossible to assess any return period for other risks, such as floods. Some of the most damaging and costly floods have occurred recently in Europe or America (in the Mississippi basin in 1992, in 1998 and 2000 in England, and in Eastern Europe in 1997, 1998, 1999, 2000, and worst of all in 2002). In the late 1990s, Munich $\mathrm{Re}^{31}$ reported that the largest share of economic losses from all natural hazards were due to floods. Along with the damage from water itself (and sewage) one has to add health hazards (from contamination). Note that floods are an essential (and normal) aspect of ecological systems as a basis of the regeneration of crops and aquatic life. As mentioned in Wisner et al.," "the collapse of confidence in engineered flood prevention has allowed an increased interest in a 'living with the floods' approach to emerge". White ${ }^{33}$ called floods "known risks" because of their repetitive behaviour patterns. If rivers have "long range memory", with persistent behaviour, ${ }^{34}$ note that prevention plans influence occurrence probabilities.

For instance, as observed by counting the number of articles in the newspapers, the centennial flooding of Paris, where the river Seine should rise $8.62 \mathrm{~m}$ above normal, is expected to take place soon (the previous one was in 1910). The first mistake is to forget that the use of the concept of centennial event (related to a return period of 100 years) is related to a stochastic process with no memory: from now, we still have to wait on average 100 years before observing a centennial event. The second one, which is the most difficult to handle for actuaries is that forecasting is possible under the classical assumption that "everything remains unchanged". But in the river Seine upstream, several dams, reservoir or dykes have been built.

Example: Consider the return period of tornados in the United States ${ }^{35}$ with an estimate obtained in 1980, and another one in 2000. Figure 5 presents several aspects of changes mentioned previously:

- The graph on the top left is the standard return period, based on 1980 data, with, on the bottom, the number of events to expect before reaching a loss event, and its interpretation in terms of years: one had to wait - on average - for 7,000 tornados in order to have a $\$ 3$ billion loss, that is, 88 years (since in 1980 there were 80 tornados per year).

- The graph on the top right is the adaptation of the return period, due to the increase of the number of tornados per year: 80 in 1980 and 100 in 2000, or dually, 1,000

\footnotetext{
${ }^{31}$ Munich Re (1997, 1998).

32 Wisner et al. (2007).

${ }^{33}$ White (1942).

${ }^{34}$ As observed by Hurst (1951).

35 The dataset for the occurrence was obtained on http://www.spc.noaa.gov/archive/, and the model for losses was obtained from Brooks and Doswell (2001).
} 

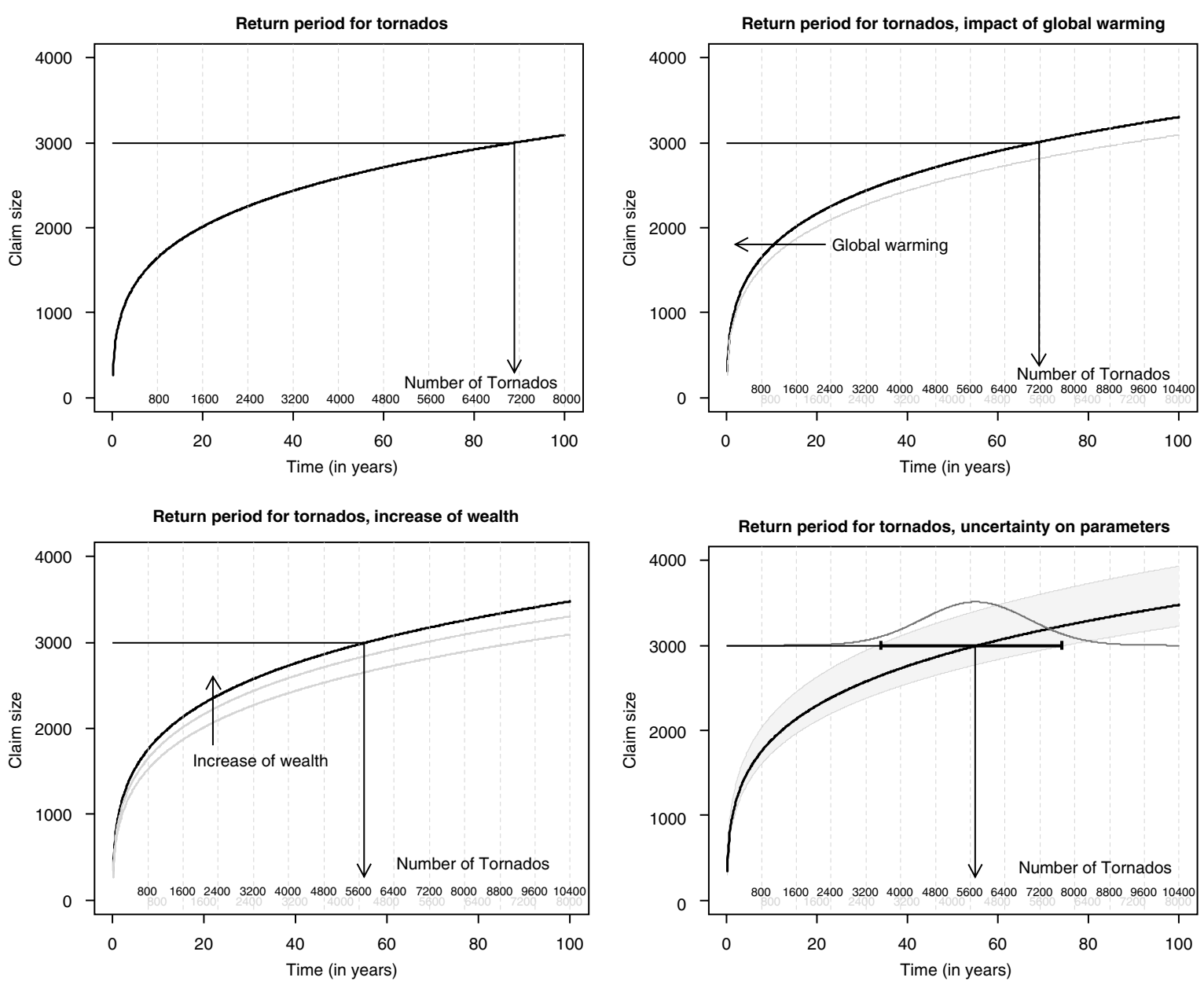

Figure 5. Modelling the return period for tornado losses in the US, including global warming, increase of wealth, and statistical uncertainty. 
tornados in 12 years in the 1980 s versus 1,000 tornados in 10 years in the 2000s: one has to wait - on average - for 7,000 tornados in order to have a $\$ 3$ billion loss, that is, 70 years (since in 2000 there were 100 tornados per year).

- The graph on the bottom left is the impact of the increase of wealth and of concentration in major areas: including inflation, this $\$ 3$ billion loss will be a $\$ 3.2$ billion loss, or dually, instead of being one claim out of 7,000, it represents one claim out of 5,600, that is, 56 years.

- The graph on the bottom right highlights the impact of uncertainty, taking into account that most of the underlying parameters of the model are rather uncertain, and thus, the graph presents a 95 per cent confidence interval for the (mean) return period. Due to uncertainty on both claim occurrence and claim size, if the interest is in the expected number of tornados to wait for before reaching the level of $\$ 3$ billion, its 90 per cent confidence interval is 3,300 and 7,800, that is, there is a 90 per cent probability that the return period of a $\$ 3$ billion dollar tornado is between 33 and 78 years.

\section{Conclusion}

Without taking into account climate change, climate risk - and more specifically natural disasters - is a challenging issue to the insurance industry, since it involves potential extremely large losses. Involving reinsurance markets and alternative risk transfer techniques (such as insurance linked securities) seems one solution to avoid insolvency problems. But, since climate is changing (and is changing fast), not only are potential losses more expensive, but they are also becoming more volatile (and therefore more risky). And, if this uncertainty cannot be reduced (by taking political measures), it might be difficult to find someone ready to pay for it.

\section{Acknowledgements}

I thank Sophie Chemarin and Pierre Picard for interesting and stimulating discussions.

\section{References}

Banham, R. (1995) 'A changing world: Science, business and risk prediction', Risk Management 42: 21-31. Berliner, B. (1982) Limits of Insurability of Risks, Upper Saddle River, NJ: Prentice-Hall.

Brooks, H.E. and Doswell, C.A. (2001) 'Some aspects of the international climatology of tornadoes by damage classification', Atmospheric Research 56: 191-201.

Charpentier, A. (2007) 'Insuring risks when pure premium is infinite?', Bulletin Français d'Actuariat 13: 67-82.

Conning \& Company (1994) Lighting Candles in the Wind: Industry Response to the Catastrophe Problem, Hartford, Connecticut (November).

Cummins, J.D., Lewis, C.M. and Phillips, R.D. (1999) 'Pricing excess-of-loss reinsurance contracts against catastrophic loss', in K. Froot (ed) The Financing of Catastrophic Risks, Chicago, IL: University of Chicago Press, pp. 92-147.

Cutler, D.M. (1996) Why Don't Markets Insure Long-Term Risk?, Working paper, Harvard University and NBER, Cambridge (May). 
Emanuel, K.A. (2005) 'Increasing destructiveness of tropical cyclones over the past 30 years', Nature 336: 686-688.

Gorvett, R.W. (1999) Insurance securitization: The development of a new asset class, Casualty Actuarial Society "Securitization of Risk" Discussion Paper Program, Arlington, VA.

Hurst, H.E. (1951) 'Long-term storage capacity of reservoirs', Transaction of the American Society of Civil Engineers 116: 770-799.

Inman, R.L. and Conover, W.J. (1980) 'Small sample sensitivity analysis techniques for computer models, with an application to risk assessment', Communications in Statistics, part A: Theory and Methods 17: 1749-1842.

IPCC (2001) 'Working group II third assessment report, technical summary', taken from http:// www.ami.ac.cn/climateChange2/IPCC_report/II9910/third/TfdTS.pdf.

Kleindorfer, P.R. and Kunreuther, H.C. (1999) 'Challenges facing the insurance industry in managing catastrophic risks', in K. Froot (ed) The Financing of Catastrophic Risks, Chicago, IL: University of Chicago Press, pp. 149-194.

Knight, F.H. (1921) Risk, Uncertainty, and Profit, Boston, MA: Hart, Schaffner \& Marx, Houghton Mifflin Company.

Knutson, T.R. and Tuleya, R.E. (2004) 'Impact of $\mathrm{CO}_{2}$-induced warming on simulated hurricane intensity and precipitation: Sensitivity to the choice of climate model and convective parameterization', Journal of Climate 17: 3477-3495.

Kunreuther, H. (2001) 'Mitigation and financial risk management for natural hazards', The Geneva Papers on Risk and Insurance - Issues and Practice 26: 276-295.

Kunreuther, H. (2006) 'Risk and reaction: Dealing with interdependencies', Harvard International Review 28(3): $6 \mathrm{pp}$.

Kunreuther, H., Ginsberg, R., Miller, L., Sagi, P., Slovic, P., Borkan, B. and Katz, N. (1978) Disaster Insurance Protection: Public Policy Lessons, New York: John Wiley.

Kunreuther, H. and Pauly, M. (2004) 'Neglecting disaster: Why don't people insure Against Large Losses?', Journal of Risk and Uncertainty 28: 5-21.

Landsea, C.W., Harper, B.A., Hoarau, K. and Knaff, J.A. (2006) 'Can we detect trends in extreme tropical cyclones?', Science 313: 452-454.

Leggett, J. (1993) 'Who will underwrite the hurricane?', New Scientist 139: 28-33.

Mayers, D. and Smith, C. (1982) 'On corporate demand for insurance', The Journal of Business 55: 281-296.

McGuire, B., Mason, I. and Kilburn, C. (2002) Natural Hazards and Environmental Changes, New York: A Hodder Arnold Publication.

Mills, E., Roth, R.J. and Lecomte, E. (2005) Availability and Affordability of Insurance Under Climate Change: A Growing Challenge for the US, Boston: Ceres, http://www.ceres.org/pub/docs.

Moss, A. (2004) When All Else Fails: Government as the Ultimate Risk Manager, Cambridge, MA: Harvard University Press.

Munich Re (1997) Annual Review of Natural Catastrophes 1997, Munich: Munich Re, http:// www.munichre.com/.

Munich Re (1998) Annual Review of Natural Catastrophes 1998, Munich: Munich Re.

Nott, J. (2003) 'The importance of prehistoric data and variability of hazard regimes in natural risks assessment: Example of Australia', Natural Hazards 30: 43-58.

Pielke Jr., R.A. and Landsea, C.W. (1998) 'Normalized U.S. hurricane damage 1925-1995', Weather Forecasting 13: 621-631.

San Diego Union-Tribune (2004) 'Changes in climate pose greatest challenge for insurers, say experts from around world', San Diego Union Tribune, April 23rd.

Stover, C.W. and Coffman, J.L. (1993) Seismicity of the United States, 1568-1989 (Revised), U.S. Geological Survey Professional Paper 1527.

Swiss Re (2006) 'Natural catastrophes and man-made disasters 2005', Swiss Re, Zurich, http:// www.swissre.com/.

Webster, P.J., Holland, G.J., Curry, J.A. and Chang, H.R. (2005) 'Changes in tropical cyclone number, duration, and intensity in a warming environment', Science 309: 1844-1846.

White, G. (1942) Human Adjustment to Floods, Research Paper 29, Chicago: University of Chicago. 
Wisner, B., Blaikie, P., Cannons, T. and Davis, I. (2007) At Risk: Natural Hazards, People's Vulnerability and Disasters, New York: Routledge.

Zajdenweber, D. (1996) 'Extreme values in business interruption', Journal of Risk and Insurance 63: 95-110. Zajdenweber, D. (2001) Economie des extrêmes, Paris: Flammarion.

\begin{abstract}
About the Author
Arthur Charpentier has been working as an actuary for an insurance company, and for the French Federation of Insurance Companies (FFSA), before obtaining his Ph.D. at the Katholieke Universiteit Leuven. He has published several papers, and two books on non-life insurance with Michel Denuit. He has been in charge of the actuarial programme at the ENSAE (National School in Statistics).
\end{abstract}

